\title{
Análise de uma crônica-reportagem à luz da teoria da Argumentação na Língua
}

\author{
Analysis of a narrative-report in the light of the Theory of \\ Argumentation in Language
}

Neiva Maria Tebaldi Gomes

Centro Universitário Ritter dos Reis/Laureate - Porto Alegre - Rio Grande do Sul - Brasil

Resumo: Este artigo analisa a constituição de sentidos de uma narrativa à luz da teoria da Argumentação na Língua, proposta inicialmente por Oswald Ducrot e Jean Anscombre. Objeto de análise, a crônica-reportagem "História de um olhar" é uma das 21 histórias de "A vida que ninguém vê", um livro de Eliane Brum, jornalista brasileira que tem se destacado no jornalismo literário. A análise realizada com o suporte da teoria da Argumentação na Língua e, paralelamente, com um olhar sobre a sintaxe textual, revela que a estrutura dos enunciados, no início da crônica fragmentados, vai se modificando à medida que a identidade da personagem protagonizada vai sendo ressignificada. Tem-se, então, uma narrativa cuja sintaxe contribui para a definição dos sentidos da narrativa.

Palavras-chave: Narrativa. Enunciados. Encadeamentos. Sentidos.

\begin{abstract}
This article analyzes the construction of meanings of a narrative in the light of the theory of argumentation in language, proposed by Oswald Ducrot and Jean Anscombre. The object of analysis, the narrative "História de um olhar" [Story of a look] is one among 21 stories from "A vida que ninguém vê" [The life that nobody sees], a book by Eliane Brum, who a Brazilian journalist that has excelled in literary journalism. The analysis, which was conducted with the support of the theory of argumentation in language and, in parallel, with a view at textual syntax, revealed that the structure of the utterances, fragmented at the beginning of the narrative, is modified as the identity of the starring character is being resignified. A narrative whose syntax contributes to the definition of the meanings of the narrative then arises.
\end{abstract}

Key-words: Narrative. Utterances. Chains. Meanings. 


\section{Sobre narratologia: breve introdução}

Este artigo tem como objeto de estudo uma crônica-reportagem que, por sua linguagem, inscreve-se na esfera do jornalismo literário. Como crônica, organiza-se com a exposição de acontecimentos mais ou menos encadeados, constituindo uma narrativa. A análise foca a estrutura dessa narrativa constituindo-se, por isso, em um estudo de narratologia, embora não se efetue pela óptica de uma teoria semiótica, mas da teoria da Argumentação na Língua.

No Nuevo diccionario enciclopédico de las ciencias del lenguaje (DUCROT; SCHAEFFER, 1998), o verbete narratologia é apresentado como um termo que foi proposto por T. Todorov para designar uma ciência ainda inexistente. Os autores salientam, contudo, que a narratologia não nasceu do nada, mas que os trabalhos nos quais ela se inspira ou dentro dos quais ela se reconhece são muito diversos e se inscrevem dentro de tradições culturais que permaneceram impermeáveis, pelo menos até uma época mais recente.

As primeiras definições do modo narrativo (diegese em oposição a mimese), segundo essa mesma fonte, encontram-se em Platão e Aristóteles. Segundo o dicionário citado, a discussão sobre a verdadeira oposição entre esses dois modos é quase tudo que se teve sobre teoria narrativa até o fim do século XIX. Mas os autores afirmam que, a partir do meio desse mesmo século (sec. XIX), o foco de atenção começa mudar, como 0 atesta a Correspondência de Flaubert. Nos romances, começam ter destaque diversos modos de apresentação dos acontecimentos ou pontos de vista: o autor está ausente, os acontecimentos se colocam diretamente aos olhos do leitor (visão cénica); o autor omnisciente resume para o leitor os acontecimentos envolvidos na narrativa (visão panorâmica); a análise repousa na distinção entre "mostrar" e "contar", oposição interna ao modo narrativo, herdada da distinção entre mimese e diegese. Nesse mesmo período, também segundo o dicionário referido, desenvolvem-se, na Alemanha, estudos narrativos que exaltam, inicialmente, o apagamento do autor. Seguem-se estudos filosóficos que procuram definir a essência da arte narrativa, deduzindo princípios independentemente da observação empírica dos fatos.

$\mathrm{Na}$ França, no fim dos anos sessenta do século $\mathrm{XX}$, desenvolvem-se estudos teóricos que buscam a estrutura comum a todas as narrativas. Destacam-se, na afirmação do caráter científico de sua busca, Barthes e Todorov. O método indutivo das ciências experimentais, à época, mostrava-se inaplicável à infinidade heteróclita de narrativas. É a linguística, com seu método dedutivo, que vai servir de modelo à análise estrutural da narrativa.

No dicionário citado, a definição do verbete "narratologia" se estende da página 228 a 240. Vários estudiosos do tema são trazidos pelos autores na tentativa de elucidar esse conceito e suas diferentes abordagens. Para os fins a que se propõe o presente estudo, no entanto, interessa sobremaneira a percepção (p. 239) de que, combinando vários níveis de análise - semântica, sintaxe, pragmática -, a narratologia se beneficiaria. Motivada por essa percepção, a análise que é apresentada neste artigo foca dois níveis: o semântico, pela teoria da Argumentação na Língua (ANL), e o sintático, no sentido amplo a que nos remete Benveniste (1989, p. 86), o das "das grandes funções sintáticas" de que o locutor se serve para influenciar de algum modo o interlocutor.

Quanto à sua organização, na próxima seção, este texto apresenta conceitos e princípios básicos da teoria que lhe dá suporte e, na seguinte, traz a análise da crônica História de um olhar, uma das 21 crônicas de "A vida que ninguém vê", livro da jornalista brasileira Eliane Brum. Na seção final, embora o autor empírico não seja contemplado pela teoria da Argumentação na Língua, o texto finaliza com um breve comentário sobre o trabalho da autora com o objetivo demonstrar que o gênero reportagem pode tornar-se arte ao desvelar acontecimentos invisíveis aos olhares desatentos. 


\section{Sobre a teoria que embasa a análise: teoria da Argumentação na Língua}

A teoria da Argumentação na Língua (ANL) é uma teoria do sentido que se opõe à concepção tradicional, como o esclarece Ducrot na primeira de uma série de conferências proferidas na Universidad del Valle (em Cali, Colômbia), posteriormente, em 1988, publicadas em livro. Segundo o autor (p. 4964), pela teoria tradicional, como em trabalhos do linguista alemão Karl Bühler, são reconhecidas três funções principais na língua: a representação da realidade (indicações objetivas), a expressão das atitudes do locutor (indicações subjetivas), a ação do locutor sobre 0 interlocutor (indicações intersubjetivas).

Por essa concepção, em enunciados como (1) Pedro é inteligente, o aspecto objetivo consistiria na descrição de Pedro; o subjetivo em uma espécie de admiração do locutor em relação a Pedro; o intersubjetivo, na possibilidade de influência que essa escolha poderia exercer sobre o interlocutor. Ducrot critica a teoria tradicional, dizendo não crer que a linguagem ordinária possua uma parte objetiva, nem que ela dê acesso direto à realidade. Nas palavras do autor:

No creo que el linguaje ordinário posea una parte objetiva ni tampoco creo que los enunciados del linguaje den acceso a la realidad; en todo caso no la describren diretamente. A mi modo de ver, si el linguaje ordinário la describe, lo hace por intermédio de los aspectos subjetivo e intersubjetivo. (DUCROT, 1988, 50)

$\mathrm{Na}$ percepção do autor, a descrição da realidade pela linguagem consistiria em uma espécie de debate entre indivíduos, no qual estariam envolvidos apenas aspectos subjetivos e intersubjetivos. Para explicar sua recusa à possibilidade de uma descrição objetiva, Ducrot retoma o enunciado Pedro é inteligente, no qual a descrição de Pedro, segundo ele, estaria muito ligada à admiração subjetiva que Pedro desperta no locutor. Com isso quer dizer que a inteligência de Pedro não significa nada se não for levada em consideração essa admiração, porque a descrição passa pela expressão de uma atitude do locutor frente ao interlocutor. Essa é a primeira razão de sua crítica à tradição. A segunda tem a ver com 0 objetivo da ANL de unificar os aspectos subjetivos e intersubjetivos, reduzindo-os ao que define como valor argumentativo dos enunciados. Por essa proposição, o valor argumentativo, que resulta de aspectos subjetivos e intersubjetivos, constitui-se do conjunto de possiblidades e impossibilidades de continuação discursiva, ou seja, da orientação semântica (na teoria, uma espécie de instrução ao locutor) que a própria palavra dá ao discurso. Voltando ao enunciado (1) Pedro é inteligente, pela teoria entende-se que é a própria palavra inteligente que contém nela mesma a orientação para encadeamentos como: inteligente, portanto capaz de compreender, inteligente portanto capaz de dar conta da tarefa, inteligente portanto capaz de resolver o problema etc.

Quanto à origem da teoria, Ducrot (CAREL; DUCROT. 2005, p.11) afirma que, em termos gerais, a Teoria da Argumentação na Língua é uma aplicação do estruturalismo saussuriano a uma semântica linguística, na medida em que, para Saussure, o significado de uma expressão reside nas relações dessa expressão com as outras expressões da língua. Essa ideia pode ser confirmada no Curso de Linguística Geral (2012 p. 171-172), segundo o qual em um estado de língua tudo se baseia em relações e diferenças que se desenvolvem em duas esferas linguísticas distintas: de um lado, no discurso, os termos estabelecem entre si, em virtude de seu encadeamento, relações baseadas no caráter linear da língua (re-ler, a vida humana, se fizer bom tempo, sairemos); por outro, fora do discurso, as palavras que oferecem algo em comum, seja em relação ao sentido, seja em relação à forma, associam-se na memória formando grupos de natureza distinta. Assim, Ensino associa-se a ensinar e a ensinamento, mas também à aprendizagem e à educação e, por outro tipo de relação (a de natureza morfológica), ensinamento pode lembrar confinamento, surgimento, etc. As relações de 
caráter linear, que têm por base a extensão, denominam-se relações sintagmáticas. O sintagma resultante dessas relações compõe-se de duas ou mais unidades consecutivas. As outras, as que têm sede no cérebro, denominam-se relações associativas e fazem parte do "tesouro interior que constitui a língua de cada indivíduo".

Segundo Ducrot, dado que a ideia de "relação" em Saussure é relativamente vaga, a ANL propõe considerar como relações semanticamente pertinentes as argumentativas, ou seja, as possibilidades de encadeamentos argumentativos em portanto entre um signo e outro (portanto é um conector abstrato que pode materializar-se em inúmeros outros, então, por isso etc.). Para o autor, as possibilidades de encadeamentos estão contidas na orientação/instrução que é fornecida pelas próprias unidades linguísticas.

Como síntese dessa primeira parte, pode-se dizer que a teoria da Argumentação na Língua, ou Semântica Argumentativa, desenvolvida, inicialmente, por Oswald Ducrot e Jean Anscombre, parte do princípio de que o sentido de um discurso é produzido pelas relações que são estabelecidas entre as palavras que o compõem. Trata-se de uma teoria segundo a qual a significação de uma palavra é definida pelas possibilidades de combinação com outra ou com outras palavras. Essas possibilidades já estão previstas na língua, por isso diz-se, na teoria, que a significação está na língua. Da concretização dessas combinações possíveis, resultam os enunciados, que contêm sentidos. Um enunciado é uma unidade de sentido e é formado de dois segmentos, articulados por um conector (explícito ou implícito). Os segmentos que constituem um enunciado são, do ponto de vista semântico, interdependentes, ou seja, o primeiro segmento só adquire sentido pela relação que estabelece com o segundo, com o qual constitui uma unidade semântica indecomponível.

Os conceitos brevemente apresentados até aqui - "relação", "sentido", "enunciado", "orientação/instrução" e "encadeamento" - dão suporte à análise que constitui a próxima seção. É preciso esclarecer, no entanto, que não se trata de uma análise exaustiva, nem de uma análise que segue rigorosamente a metodologia proposta pela teoria da Argumentação na Língua. Mas a teoria está presente na medida em que os sentidos são descritos a partir do encadeamento de alguns dos enunciados que compõem o discurso da crônica que é objeto de estudo. O termo discurso é empregado para definir o conjunto de enunciados que compõem um todo significativo, a crônica. Para efeito de análise, a segmentação dos enunciados realizou-se pela pontuação, de tal forma que o ponto final serviu para delimitar as unidades significativas. A análise se amplia com um olhar sobre a organização sintática dos enunciados no discurso, bem como dos efeitos de sentido produzidos por essa organização.

\section{História de um olhar: uma análise preliminar à luz da teoria da Argumentação na Língua}

A crônica de Eliane Brum, um discurso que narra a redenção de um personagem anônimo que foi salvo pelo olhar de uma professora, constrói-se semanticamente a partir do encadeamento de enunciados que especificam o olhar referido no sintagma que a intitula: História de um olhar.

O mundo é salvo por um olhar. Que envolve e afaga. Abarca. Resgata. Reconhece. Salva. (linhas 3 e 4).

Essa sequência de enunciados aparentemente fragmentados, pela orientação das próprias palavras que os constituem, revela desde o início os seguintes encadeamentos argumentativos: olhar portanto enxergar; enxergar portanto reconhecer; reconhecer portanto salvar. Por se tratar de encadeamentos em portanto, na teoria diz-se serem normativos. E se há um olhar assim caracterizado é porque há um outro olhar pressuposto: olhar no entanto não enxergar (e portanto), não reconhecer e não salvar. Os encadeamentos em no entanto, também previstos na língua, são descritos, na teoria, como transgressivos. A narrativa articula-se, assim, sobre dois eixos: um 
olhar que enxerga que se opõe a um olhar que não enxerga.

O primeiro parágrafo da crônica é uma espécie de preâmbulo, isto é, uma parte preliminar em que é anunciado o poder redentor de um olhar. A articulação do primeiro parágrafo com o segundo, que é constituído por uma única palavra - "Inclui" (Linha 5) - , resulta do encadeamento argumentativo: olhar que salva portanto (ou porque) inclui. $\mathrm{O}$ parágrafo com uma única palavra, aparentemente desarticulado, antecipa a síntese da narrativa: um olhar redentor.

O terceiro parágrafo define a história do olhar que é tema da crônica; o quarto apresenta os personagens sobre os quais se constrói a crônica, a professora Eliane e o andarilho Israel Pires.

O quinto parágrafo contextualiza a história do olhar na vila (Vila Kephas) construída por operários de uma indústria, hoje desempregados: "Biscateiros. Papeleiros. Excluídos".

O parágrafo seguinte $\left(6^{\circ}\right)$ descreve a vila onde vagava Israel: "O enjeitado da vila enjeitada. A imagem indesejada no espelho."

O sétimo parágrafo, construído basicamente de enunciados fragmentados (do ponto de vista da sintaxe tradicional), revela uma progressão argumentativa que vai do adjetivo imundo ao substantivo escória, que permite a seguinte descrição semântica: Israel era a escória portanto desprezível (e, por isso, escorraçado como um cão, torturado, cuspido, apedrejado).

Imundo, meio abilolado, malcheiroso, Israel vivia atirado num canto ou noutro da vila. Filho de pai pedreiro e de mãe morta, vivendo em uma casa cheia de fome com a madrasta e uma irmã doente. Desregulado das ideias, segundo o senso comum. Nascido prematuro, mas sem dinheiro para diagnóstico. Escorraçado como um cão, torturado pelos garotos maus. Amarrado, quase violado. Israel era cuspido. Era apedrejado. Israel era a escória.

No oitavo parágrafo, a narrativa assume outra orientação argumentativa: a expressão temporal "Um dia" (Um dia Israel se aproximou de um menino), que constitui uma marca linguística de progressão textual, permite encadear novos acontecimentos: Israel se aproximou do menino, que era seu oposto (bom de bola, bom de rua) e de tanto gostar dele seguiu-o até a escola onde as crianças recebiam cucas e leite. $\mathrm{E}$ chegou porque tinha fome. De comida, de afago, de lápis de cor. Fome de olhar.

O nono parágrafo inicia com "Aconteceu neste inverno" em que o verbo "acontecer", por sua argumentação interna, orienta o interlocutor para buscar um sentido como processo que afeta algo ou alguém, algo significativo: a professora descobriu Israel. O verbo descobrir por sua composição morfológica (des + cobrir) pode ser parafraseado por fazer aparecer. Entre os termos utilizados pelo locutor para descrever esse aparecimento de Israel, tem-se "espectro", termo que poderia ser parafraseado por aparição como defunto ou como ilusão; e "olhos de vira-lata pidão", portanto de abandono, de súplica.

No parágrafo seguinte $\left(10^{\circ}\right)$, a reciprocidade expressa pelo emprego de verbo ver (Eliane viu Israel. E Israel se viu refletido no olhar de Eliane. E o que se passou naquele olhar é um milagre de gente) constituiu o milagre: o Israel que fora descoberto pela professora agora descobre outro Israel. O termo milagre, por sua argumentação interna, pode ser parafraseado por "acontecimento fora do comum, inexplicável pelas leis naturais". O acontecimento fora do comum é explicado no último enunciado do parágrafo: Israel descobriu nos olhos da professora que era um homem, não um escombro. O verbo "descobrir" é novamente empregado, mas agora não mais como ação da professora, mas do próprio Israel. A negação "não um escombro" contém o pressuposto escombro portanto entulho, algo a ser descartado, excluído, que era como o Israel da narrativa se percebia antes de ser salvo pelo olhar da professora.

O décimo primeiro parágrafo confirma a salvação pelo olhar: "Israel perseguiu o olho de espelho da professora" que refletia a imagem de um homem, não de um escombro. E por causa dessa imagem, quando viram, Israel estava na janela da sala de aula da $2^{a}$ série $C$. Com meio corpo para 
dentro do olhar da professora. (Note-se: meio corpo dentro, não mais da janela da sala de aula, mas do olhar da professora).

A partir do quarto enunciado do décimo segundo parágrafo, a narrativa assume uma nova orientação argumentativa: Israel completa a subversão que vinha aos poucos se delineando. Essa reorientação vem marcada pelo conector Mas, que não articula apenas dois enunciados, mas define dois momentos da narrativa: a passagem do Israel abilolado, mal cheiroso, desajeitado, acossado para o Israel que "chegou de banho tomado, barba feita, roupa limpa" (13ำ parágrafo). O conector E orienta para a continuidade da "subversão", que tem sua progressão narrativa marcada pelo sintagma adverbial num dia de agosto.

\begin{abstract}
Mas devagar, como bicho acuado, que de tanto apanhar ficou ressabiado, foi pegando primeiro um lápis, depois um afago. E, num dia de agosto, Israel completou a subversão. Cruzou a porta e pintou bonecos de papel. Israel estava todo dentro do olhar da professora.
\end{abstract}

Os enunciados do parágrafo seguinte $\left(13^{\circ}\right)$ articulam-se ampliando o sentido de "olhar" de inclusão: $E$ o olhar começou a se espalhar, se expandir e engolfou toda a sala de aula. A imagem se multiplicou por 31 pares de olhos de crianças.

$\mathrm{Na}$ sequência da narrativa, os enunciados explicitam a transformação:

Israel chegou de banho tomado, barba feita, roupa limpa. Igualzinho ao Israel que havia avistado no olho da professora. Trazia umas pupilas novas [...]. E um sorriso recéminventado. Entrou na sala e ela começou a chorar. E as lágrimas da professora, tal qual um vagalhão, terminaram de lavar a imagem acossada, ferida, flagelada de Israel.

Os enunciados seguintes vão revelando esse processo de transformação que culmina com a redenção de Israel (17ํำ parágrafo): redenção portanto resgate; portanto salvação. A argumentação interna do termo redenção tem origem na Teologia e significa o resgate do gênero humano por Cristo; na crônica, significa o resgate de Israel pelo olhar da professora e, ao mesmo tempo, o resgate da professora, que depois que se descobriu no olhar de Israel, ri sozinha e chora à toa. [...] A redenção de Israel foi (também) a revolução da professora.

A partir do décimo segundo parágrafo, a transformação de Israel demonstrada pelo encadeamento de enunciados está também marcada na organização sintática da crônica: os parágrafos que, na primeira parte são constituídos por enunciados fragmentados, passam a ser estruturados com enunciados sintaticamente menos fragmentados e mais coesos em sua materialidade linguística. Tem-se, então, uma narrativa cuja sintaxe textual (sintaxe entendida aqui como a estruturação dos enunciados e sua articulação no discurso) contribui para a definição dos sentidos: o "enjeitado da vila enjeitada" (6ำ parágrafo) transforma-se, pelo olhar da professora, em um Israel que, Em 7 de Setembro, desfilou. Pintado de verde-amarelo, aplaudido de pé pela Vila Pedra.

\section{Sobre o autor empírico do discurso: algumas considerações}

Escrevo porque a vida me dói, porque não seria capaz de viver sem transformar dor em palavra escrita. Mas não é só dor o que vejo no mundo. É também delicadeza, uma abissal delicadeza, e é com ela que alimento a minha fome. (Eliane Brum)

A Teoria da Argumentação na Língua rompe com a ideia de unicidade do sujeito falante ao propor a existência, em um mesmo enunciado, de vários sujeitos com status linguísticos diferentes: um sujeito empírico ou produtor do enunciado (que não interessa na descrição dos sentidos), um locutor (que é o responsável pelo enunciado) e um enunciador ou enunciadores (que são pontos de vista que se revelam no enunciado, mais especificamente, por meio de pressupostos linguísticos). Nesse contexto teórico, fica claro que o locutor não se confunde com o produtor empírico do enunciado, na crônica analisada, a jornalista Eliane Brum. Embora não sejam considerados na teoria da Argumentação na Língua, para efeito de descrição de sentidos, dados sobre o autor são aspectos relevantes em estudos que levam em consideração o contexto 
extralinguístico de produção e em trabalhos de crítica literária.

Do ponto de vista do contexto extralinguístico, Eliane Brum (Jornalista gaúcha que já recebeu mais de 40 prêmios, entre os recebidos no Brasil e no exterior) é definida pelos críticos como uma repórter que busca nos acontecimentos que não viram notícia e nas pessoas que não são celebridades a substância dos seus escritos. Uma escritora que mergulha no cotidiano para provar que não existem vidas comuns. Suas crônicas-reportagens contam histórias como a de Israel que emocionam pela sensibilidade que revelam e pela agudeza do olhar de uma repórter que, como ela mesma diz, para sobreviver precisa transformar "dor em palavra escrita".

\section{Referências}

BENVENISTE, Émile. Problemas de Linguística Geral II. Trad. Eduardo Guimarães et al. Campinas, SP: Pontes, 1989. 294 p.

BRUM, Eliane. A vida que ninguém vê. Porto Alegre: Arquipélago Editorial, 2006.

CAREL, Marion; DUCROT, Oswald. La Semántica Argumentativa: una introducción a la teoria de los Bloques Semánticos. Edición e Trad. María Marta G. Negroni e Alfredo M. Lescano. Buenos Aires: Colihue, 2005. 231 p.

DUCROT, Oswald; SCHAEFFER, Jean-Marie. Nuevo diccionario enciclopédico de las ciencias del lenguaje. Edición espanhola dirigida por Marta Tordesilhas. Arrecife Producciones, S.E.: Madri,1998. P.228-240.

DUCROT, Oswald. Polifonia y Argumentación. Conferencias del seminário Teoria de la Argumentación y analisis del discurso. Universidad del Valle. Cali. 1988. p. 49-64.

SAUSSURE, Ferdinand de. Curso de Linguística Gera. 28ª edição, São Paulo: Cultrix, 2012. 312 p.

\section{COMO CITAR ESSE ARTIGO}

TEBALDI GOMES, Neiva Maria. Análise de uma crônica-reportagem à luz da teoria da Argumentação na Língua. Signo, Santa Cruz do Sul, v. 42, n. 73, jan. 2017. ISSN 1982-2014. Disponível em: $<$ https://online.unisc.br/seer/index.php/signo/article/view/8008>. Acesso em: http://dx.doi.org/10.17058/signo.v42i73.8008. 


\section{ANEXO}

\section{HISTÓRIA DE UM OLHAR}

(1) O mundo é salvo todos os dias por pequenos gestos. Diminutos, invisíveis. O mundo é salvo pelo avesso da importância. Pelo anônimo da evidência. O mundo é salvo por um olhar. Que envolve e afaga. Abarca. Resgata. Reconhece. Salva.

(2) Inclui.

(3) Esta é a história de um olhar. Um olhar que enxerga. $E$ por enxergar, reconhece. $E$ por reconhecer, salva.

(4) Esta é a história do olhar de uma professora chamada Eliane Vanti e de um andarilho chamado Israel Pires.

(5) Um olhar que nasceu na Vila Kephas. Dizem que, em grego, kephas significa pedra. Por isso um nome tão singular para uma vila de Novo Hamburgo. Kephas foi inventada mais de uma década atrás pedra sobre pedra. Em regime de mutirão. Eram operários da indústria naqueles tempos nada longínquos. Hoje, desempregados da indústria. Biscateiros, papeleiros. Excluídos.

(6) Nesta Kephas cheia de presságios e de misérias vagava um rapaz de 29 anos com o nome de Israel. Porque em todo lugar, por mais cinzento, trágico e desesperançado que seja, há sempre alguém para ser chutado por expressar a imagemsíntese, renegada e assustadora, do grupo. Israel, para a Vila Kephas, era esse ícone. O enjeitado da vila enjeitada. A imagem indesejada no espelho.

(7) Imundo, meio abilolado, malcheiroso, Israel vivia atirado num canto ou noutro da vila. Filho de pai pedreiro e de mãe morta, vivendo em uma casa cheia de fome com a madrasta e uma irmã doente. Desregulado das ideias, segundo o senso comum. Nascido prematuro, mas sem dinheiro para diagnóstico. Escorraçado como um cão, torturado pelos garotos maus. Amarrado, quase violado. Israel era cuspido. Era apedrejado. Israel era a escória.

(8) Um dia Israel se aproximou de um menino. De nove anos, chamado Lucas. Olhos de amêndoa, rosto de esconderijo. Bom de bola. Bom de rua. De tanto gostar do menino que Ihe sorriu. Israel o seguiu até a escola. Até a porta onde Lucas desaparecia todas as tardes, tragado sabe-se lá por qual magia. Até a porta onde as crianças recebiam cucas e leite. Israel chegou até lá por fome. De comida, de afago, de lápis de cor. Fome de olhar.

(9) Aconteceu neste inverno. Eliane, a professora, descobriu Israel. Desajeitado, envergonhado, quase desaparecido dentro dele mesmo. Um vulto, um espectro na porta da escola. Com um sorriso inocente e uns olhos de vira-lata pidão, dando a cara para bater porque nunca foi capaz de escondê-la.

(10) Eliane viu Israel. E Israel se viu refletido no olhar de Eliane. E o que se passou naquele olhar é um milagre de gente. Israel descobriu um outro Israel navegando nas pupilas da professora. Terno, especial, até meio garboso. Israel descobriu nos olhos da professora que era um homem, não um escombro.

(11 Capturado por essa irresistível imagem de si mesmo, Israel perseguiu o olho de espelho da professora. A cada dia dava um passo para dentro do olhar. E, quando perceberam, Israel estava no interior da escola. E, quando viram, Israel estava na janela da sala de aula da $2^{a}$ série C. Com meio corpo para dentro do olhar da professora.

(12) Uma cena e tanto. Israel na janela, espiando com os olhos. Quando o chamavam, fugia correndo. Escondia-se atrás dos prédios. Mas devagar, como bicho acuado, que de tanto apanhar ficou ressabiado, foi pegando primeiro um lápis, depois um afago. E, num dia de agosto, Israel completou a subversão. Cruzou a porta e pintou bonecos de 
papel. Israel estava todo dentro do olhar da professora.

(13) E o olhar começou a se espalhar, se expandir, e engolfou toda a sala de aula. A imagem se multiplicou por 31 pares de olhos de crianças. Israel, o pária, tinha se transformado em Israel, o amigo. Ganhou roupas, ganhou pasta, ganhou lápis de cor. E, no dia seguinte, Israel chegou de banho tomado, barba feita, roupa limpa. Igualzinho ao Israel que havia avistado no olho da professora. Trazia até umas pupilas novas, enormes, em forma de facho. E um sorriso também recém-inventado. Entrou na sala onde a professora pintava no chão e ela começou a chorar. E as lágrimas da professora, tal qual um vagalhão, terminaram de lavar a imagem acossada, ferida, flagelada de Israel.

(14) Israel, capturado pelo olhar da professora, nunca mais o abandonou. Vive hoje nesse olhar em formato de sala de aula, cercado por 31 pares de olhos de infância que lhe contam histórias, puxam a mão e Ihe ensinam palavras novas. Refletido por esses olhos, Israel passou a refletir todos eles. E a professora, que andava deprimida e de mal com a vida, descobriu-se bela, importante, nos olhos de Israel. E as crianças, que têm na escola um intervalo entre a violência e a fome, descobriram-se livres de todos os destinos traçados nos olhos de Israel.

(15) Israel, não importa se alguém não gosta de você. O que importa é que você siga a vida, aconselha Jéferson, de oito anos. Israel, não faz mal que tu sejas grande e um pouco doente, tu podes fazer tudo o que imaginares, promete Greice, de nove. Israel, se alguém te atirar uma pedra eu vou chamar o Vandinho, porque todo mundo tem medo do Vandinho, tranquiliza Lucas, nove. Israel, tu me botas na garupa no recreio?

(16) E foi assim que o olhar escorreu pela escola e amoleceu as ruas de pedra.

(17) Israel, depois que se descobriu no olhar da professora, ganhou o respeito da vila, a admiração do pai. Vai ganhar uma vaga oficial na escola. Já consegue escrever o "P" de professora. E ninguém mais the atira pedras. A professora, depois que se descobriu no olhar de Israel, ri sozinha e chora à toa. Parou de reclamar da vida e as aulas viraram uma cantoria. A redenção de Israel foi a revolução da professora.

(18) Em 7 de Setembro, Israel desfilou. Pintado de verde-amarelo, aplaudido de pé pela Vila Pedra. 